\title{
Singularidade fenomênica e conteúdo perceptivo
}

\author{
Marco Aurélio Sousa Alves
}

Universidade Federal de São João del-Rei

Campus Alto Paraopeba, Ouro Branco, Minas Gerais

Brasil

marcoaurelioalves@ufsj.edu.br

Article info

CDD: 121.3

Received: 11.11.2017; Accepted: 07.12.2017

DOI: http://dx.doi.org/10.1590/0100-6045.2018.V41N1.MA

\section{Keywords:}

Conteúdo perceptiv

Singularidade fenomênica

Singularidade ontológica

Representacionalismo

Realismo ingênuo
Perceptual content

Phenomenal singularity

Ontological singularity

Representationalism

Naïve realism

\section{RESUMO}

As principais teorias do conteúdo perceptivo são incapazes de explicar o caráter fenomênico singular da experiência perceptiva. Tal dificuldade, conforme argumento, se origina da ausência de uma série de distinções que acaba tornando o problema aparentemente insolúvel. Após analisar brevemente as principais deficiências da teoria representacionalista e do realismo ingênuo, apresento uma proposta que pretende tornar não problemático o fato trivial de percebermos objetos particulares que se apresentam enquanto tais em nossas experiências perceptivas. A proposta, assim como a crítica às demais alternativas, são reconhecidamente apresentadas de forma breve e esquemática. Espera-se ao menos justificar que o caminho proposto é promissor e vale a aposta.

\begin{abstract}
The most prominent theories of perceptual content are incapable of accounting for the phenomenal particularity of perceptual experience. This difficulty, or so I argue, springs from the absence of a series of distinctions that end up turning the problem apparently unsolvable. After briefly examining the main shortcomings of representationalism and naïve realism, I advance a proposal of my own that aims to make the trivial fact of perceptually experiencing a particular object as such philosophically unproblematic. Though I am well aware of the sketchy and schematic way in which my proposal is advanced and the other alternatives are criticized, I hope this paper is still worth its ink at least insofar as it is capable of pointing to a novel and promising way out of old and resilient difficulties that have been haunting philosophers of perception. If not a fully developed theory, at least I deliver here a sketch that, or so I sell, is worth the bet.
\end{abstract}

Manuscrito - Rev. Int. Fil. Campinas, v. 41, n. 1, pp. 67-91, jan.-mar. 2018. 


\section{Considerações iniciais}

Estou sentado em uma carteira e vejo o Ernesto entrar na sala de aula. Vejo, então, entre outras coisas, o Ernesto, de carne e osso, que anda de um lado para o outro enquanto fala de um tema qualquer em filosofia da linguagem. Tipicamente, em nossas experiências perceptivas, percebemos objetos ordinários como o Ernesto, que se apresentam para nós como particulares (i.e. discretos e numericamente distintos). Vemos o Ernesto entrar nesta sala, ou aquele pássaro pousar naquela árvore. A particularidade é constitutiva do caráter fenomênico (what-it's-likeness) da experiência. Não percebemos apenas propriedades gerais (e.g. cores, formas, timbres sonoros, posições relativas), mas também objetos particulares que preenchem o ambiente à nossa volta.

O caráter singular da experiência perceptiva tem uma dimensão fenomenológica. Como afirma Montague (2011, p. 121), "é parte do caráter qualitativo de muitas das nossas experiências (...) que elas são experiências de objetos particulares individuais". ${ }^{1}$ Ao ver o Ernesto, não estou apenas numa relação qualquer com um objeto mundano, mas a minha experiência é tal que o mundo se apresenta para mim como havendo um objeto particular à minha frente. Se a experiência é verídica, vejo essa coisa, e não qualquer outra coisa, mesmo que idêntica em todas suas propriedades perceptíveis. Quando vejo o Ernesto, o vejo como algo único e numericamente distinto de qualquer outra coisa. $^{2}$

${ }^{1}$ Essa e todas as demais traduções nesse artigo são de minha autoria. No original: "It is part of the experiential qualitative character of many of our experiences (...) that they are experiences of individual particular objects." (Montague, 2011, p. 121; grifo do original).

${ }^{2}$ A afirmação de que as experiências perceptivas são tipicamente singulares num sentido propriamente fenomenológico pode ser colocada em questão. Tal afirmação é muitas vezes tomada como um mero datum fenomenológico intuitivo que não precisa ser provado, e sim explicado. Entretanto, não é tão trivial assim que isso seja o caso. Em sua defesa, podemos apelar para o fato de que a percepção de algo como um objeto particular parece fundar nossa capacidade de compreender expressões demonstrativas de re, como quando aponto para o Ernesto e digo 'esse cara foi meu professor'. A não ser que a experiência destaque um indivíduo em particular para ser o objeto da referência, tal capacidade seria misteriosa. Afinal de contas, poderia ver as mesmas propriedades perceptivas (cores, formas, etc.) como não instanciadas por um único objeto, ou como flutuando no ar, ou como parte do fundo. Pense, por exemplo, que o Ernesto está em frente a um quadro abstrato cheio de cores e formas. A não ser que o destaque desse

Manuscrito - Rev. Int. Fil. Campinas, v. 41, n. 1, pp. 67-91, jan.-mar. 2018. 
Apesar de aparentemente trivial, a constatação de que nossas experiências perceptivas tipicamente apresentam objetos particulares enquanto objetos particulares suscita grande embaraço para a teoria do conteúdo perceptivo. As principais teorias hoje em circulação enfrentam enormes dificuldades para explicar a particularidade fenomênica, ou o fato de objetos particulares serem fenomenologicamente apresentados enquanto tais em nossas experiências perceptivas. No que se segue, exponho algumas das principais dificuldades enfrentadas pelas teorias correntes. Em seguida, apresento uma proposta alternativa que, conforme argumento, oferece uma nova e promissora via para a solução do problema. No final das contas, é preciso que o fato trivial de ver o Ernesto não constitua mais um embaraço para o teórico da percepção.

\section{A experiência perceptiva}

Duas questões são fundamentais para compreender a natureza da experiência perceptiva: a questão ontológica (o que é uma experiência perceptiva?; quais seus critérios de individuação?), e a questão cognitiva (o que experiências perceptivas disponibilizam para estados cognitivos como crenças e pensamentos?; como podem fazer isso?).

As questões acima estão interligadas. A natureza ontológica da experiência precisa ser tal que torne suas relações cognitivas não problemáticas. É preciso explicar por que a experiência particular $X$ disponibiliza capacidades cognitivas específicas que a distinguem de outra experiência $Y$ qualquer. Se vejo o Ernesto entrar na sala e, por causa disso, acredito que ele já vai começar a aula, é preciso explicar como a minha experiência é capaz de racionalizar crenças desse tipo sobre o Ernesto.

Além de disponibilizar material para o pensamento, a experiência perceptiva apresenta também uma determinada qualidade fenomênica. Podemos distinguir aqui dois aspectos da experiência: o caráter fenomênico (i.e. a experiência perceptiva possui, necessariamente, uma determinada qualidade fenomênica

fundo e o perceba como um objeto particular, não poderia fazer referência a ele, ainda que represente as mesmas propriedades perceptivas em minha experiência. Nesse artigo, por uma questão de foco, não pretendo justificar tal afirmação, apesar de admitir que ela não deva ser admitida como simplesmente trivial. No que se segue, simplesmente pressuponho que experiências podem ser fenomenologicamente singulares, e então avalio como isso poderia ser explicado.

Manuscrito - Rev. Int. Fil. Campinas, v. 41, n. 1, pp. 67-91, jan.-mar. 2018. 
que lhe é intrínseca), e o caráter relacional (i.e. experiências envolvem tipicamente uma relação com objetos e propriedades do mundo; experiências de diferentes objetos constituem diferentes experiências).

O caráter relacional está intimamente ligado à questão cognitiva. Experiências de diferentes objetos são capazes de disponibilizar diferentes conteúdos para estados cognitivos superiores. Tais propriedades, assim como as propriedades fenomênicas, são intrínsecas à experiência. Se vejo o Ernesto entrar na sala, tal experiência disponibiliza pensamentos de re sobre o Ernesto. Se, ao contrário, quem entrou na sala foi o Genésio, o desconhecido irmão gêmeo idêntico do Ernesto, tal experiência não disponibiliza nem justifica crenças de re sobre o Ernesto, não importa o quão parecidos sejam Ernesto e Genésio.

O contraste cognitivo que deriva da alteração do objeto percebido fez com que teóricos das mais diferentes vertentes passassem a incluir o objeto percebido na determinação da experiência perceptiva. Isso pode ser claramente percebido entre os teóricos da chamada teoria representacionalista da mente. ${ }^{3}$ Representacionalistas usam a noção de conteúdo para desempenhar o duplo papel de determinar as condições de veracidade da experiência e fixar seu caráter fenomênico. As primeiras teorias representacionalistas, de meados dos anos 1990, estavam preocupadas primordialmente com a elaboração de um tratamento unificado da fenomenologia perceptiva, que fosse capaz de explicar experiências verídicas e inverídicas a partir dos mesmos conteúdos representacionais. Isso fez com que a contribuição do objeto percebido na determinação do conteúdo da experiência fosse problemática e, muitas vezes, negligenciada. Quando tal negligência foi percebida, a resposta amplamente

\footnotetext{
${ }^{3}$ A teoria representacionalista, talvez hoje a mais popular entre os filósofos da mente, surge em sua forma mais acabada e desenvolvida a partir dos trabalhos de Tye (1995), Dretske (1995), Lycan (1996), Crane (2001), Siegel (2010), entre muitos outros. Segundo essa perspectiva, uma experiência perceptiva é (ou 'é idêntica a') um estado representacional de determinado tipo. O estado representacional é (pelo menos parcialmente) individuado em termos de seu conteúdo, que pode ser entendido como as condições de veracidade que capturam a forma como o mundo é representado segundo a experiência. Apesar das muitas diferenças, representacionalistas de todas as vertentes concordam que a experiência perceptiva consiste fundamentalmente em um sujeito estar em um estado representacional definido em termos de seu conteúdo, que captura a forma como o ambiente é representado pela experiência e fixa (ao menos em parte) o caráter fenomênico da experiência.
}

Manuscrito - Rev. Int. Fil. Campinas, v. 41, n. 1, pp. 67-91, jan.-mar. 2018. 
adotada foi incluir o objeto no conteúdo perceptivo. Schellenberg (2013, p. 293) resume bem o tipo de consideração que levou a maioria dos representacionalistas a incluir o objeto no conteúdo perceptivo: "se as condições de veracidade mudam dependendo do objeto particular com o qual o sujeito está relacionado, e se o conteúdo determina as condições de veracidade, então o conteúdo da experiência precisa mudar dependendo de qual objeto particular está em relação com o sujeito." " Tornou-se, então, hegemônica, entre os representacionalistas, a crença de que qualquer tentativa de apreender as condições de veracidade da experiência sem apelar aos objetos percebidos estaria fadada ao fracasso.

Suponha, por exemplo, que olho para frente, mas, sem que eu saiba, um espelho engenhosamente disfarçado está inclinado de tal forma a refletir a imagem do Genésio, que se encontra na sala ao lado. ${ }^{5}$ Tal como o ambiente se apresenta para mim, vejo o que acredito ser o Ernesto na minha frente, pois desconheço a existência de seu irmão gêmeo Genésio. Suponhamos, também, que o Ernesto esteja, de fato, atrás do espelho, e instancie exatamente as mesmas propriedades perceptivas que seu irmão Genésio. Neste caso, acredito, com base na experiência, que o Ernesto está na minha frente e instancia as propriedades fenomênicas $X, Y, Z$. Minha crença é verdadeira: o Ernesto está, de fato, na minha frente, e instancia as propriedades representadas. No entanto, algo está obviamente errado nesse caso. Não vi o Ernesto, mas o Genésio; e o objeto que vi, o Genésio, não está onde acredito estar. Trata-se de um caso de ilusão, mas para entender o tipo de erro que torna essa experiência inverídica, é preciso que o tipo específico de relação sujeito-objeto, e que o objeto dessa relação, apareçam na determinação das condições de veracidade da experiência. Não basta dizer quais propriedades fenomênicas são representadas na experiência e, em seguida, olhar para o mundo para ver como ele de fato é. O exemplo acima ilustra as limitações de uma abordagem do conteúdo perceptivo que não inclua o objeto percebido.

\footnotetext{
${ }^{4}$ No original: "If the accuracy conditions change depending on what particular object one is related to, and if the content determines accuracy conditions, then the content of experience must change depending on what particular object one is related to." (Schellenberg, 2013, p. 293).

${ }^{5}$ Faço aqui uma adaptação do exemplo de Tye (2009, p. 544), que por sua vez adaptou o exemplo original de Grice (1961, p. 134).
}

Manuscrito - Rev. Int. Fil. Campinas, v. 41, n. 1, pp. 67-91, jan.-mar. 2018. 


\section{O problema}

O objeto percebido pode ser usado para determinar o conteúdo perceptivo de diferentes formas. De modo geral, os representacionalistas passaram a ver o conteúdo singular como object-involving, ou como necessariamente fazendo referência ao objeto. Dessa forma, não é possível falar em conteúdo singular na ausência do objeto percebido. Essa abordagem, no entanto, torna problemática a determinação do caráter fenomênico da experiência, que é uma das funções atribuídas ao conteúdo perceptivo. Uma das motivações iniciais dos representacionalistas, ao postularem conteúdos representacionais, era explicar a possibilidade de experiências de objetos distintos, ou mesmo de nenhum objeto, compartilharem o mesmo caráter fenomênico. Isso seria explicado pelo fato de essas experiências terem o mesmo conteúdo: o caráter fenomênico era simplesmente equalizado com o conteúdo representacional. A inclusão do objeto no conteúdo, porém, inviabiliza tal explicação.

Se vejo o Ernesto e, depois, vejo o Genésio, e se o objeto percebido é parte do conteúdo perceptivo, então tenho duas experiências com conteúdos diferentes. A primeira apresenta o Ernesto no conteúdo, enquanto a segunda apresenta o Genésio. Mesmo que ambos sejam indistinguíveis perceptualmente, e que ambas as experiências compartilhem o mesmo caráter fenomênico, o conteúdo da experiência do Ernesto será necessariamente distinto do conteúdo da experiência do Genésio. Ademais, se tenho uma alucinação fenomenologicamente idêntica à experiência de ver o Ernesto ou o Genésio, tenho ainda um terceiro estado mental que, por nem mesmo envolver uma relação perceptiva genuína com qualquer objeto particular, nunca poderá ter o mesmo conteúdo das demais, ainda que possua o mesmo caráter fenomênico.

Para lidar com o caráter fenomênico e manter o conteúdo perceptivo singular, a solução encontrada pelos representacionalistas foi, via de regra, fixar o caráter fenomênico usando a parte do conteúdo que não faz referência ao objeto percebido. Quando vejo o Ernesto, por exemplo, o vejo como instanciando várias propriedades fenomênicas (e.g. cores, distância relativa, etc.). Se tiramos o objeto do conteúdo, resta uma espécie de layout ou arranjo da experiência, composto apenas por aglomerados de propriedades (property clusters). Tal arranjo foi, então, usado para fixar o caráter fenomênico da 
experiência. ${ }^{6}$ Dessa forma, experiências de diferentes objetos podem ser fenomenologicamente idênticas. Já uma experiência alucinatória seria uma experiência não-singular que tem em seu conteúdo os mesmos arranjos de propriedades que fixam o caráter fenomênico de uma experiência singular legítima fenomenologicamente idêntica a ela.

Apesar de engenhoso, poucos perceberam que o novo aparato teórico era incapaz de explicar satisfatoriamente a singularidade fenomênica. Se a singularidade tem uma dimensão fenomênica, como afirmei na introdução, então deve haver algo no conteúdo perceptivo que possa fixar tal traço fenomênico. Ao dizer que o objeto não desempenha nenhum papel fenomênico, afirmando que apenas o restante do conteúdo seria usado para fixar a fenomenologia perceptiva, os representacionalistas eliminaram o único elemento que supostamente captaria a singularidade fenomênica. Ademais, atribuir, pura e simplesmente, papeis fenomênicos ao objeto percebido também não resolveria o problema. Como ficariam, por exemplo, as alucinações fenomenologicamente singulares? Se alucinações e experiências genuínas podem compartilhar o mesmo caráter fenomênico, e se a singularidade é uma marca dessas experiências, então deve haver algo também na alucinação que possa explicar tal característica. E esse algo, obviamente, não pode ser o objeto percebido, pois a alucinação é exatamente a experiência sem objeto. Vale lembrar que a experiência alucinatória também possui a capacidade de disponibilizar conteúdos supostamente singulares para estados cognitivos superiores. Ao ter uma alucinação, o sujeito, com base na experiência, pode

' $\mathrm{O}$ sentido em que o conteúdo 'fixa' ou 'determina' o caráter fenomênico, ou mesmo se essa relação deveria ser pensada na direção inversa, ou seja, como o caráter fenomênico fixando o conteúdo, são questões propositalmente deixadas em aberto. Isso abriria um debate no qual não pretendo me posicionar aqui, e que acredito ser ortogonal ao ponto em foco. Pretendo capturar com o uso dessa expressão apenas a ideia bem geral, comum a representacionalistas de qualquer estirpe, de que o conteúdo representacional guarda uma relação explicativa qualquer com a fenomenologia da percepção, sendo que uma coisa deve espelhar estruturalmente a outra, se não completamente, pelo menos na medida em que a fenomenologia perceptiva se deixa explicar em termos representacionais. Agradeço ao parecerista que me alertou para a necessidade de esclarecer a forma como uso tal noção, apesar de ter a estranha impressão de que ele (ou ela) não ficará muito satisfeito(a) com a minha evasão da questão. Em suma, acredito que o que tenho a dizer aqui não se compromete com uma tese substantiva a esse respeito.

Manuscrito - Rev. Int. Fil. Campinas, v. 41, n. 1, pp. 67-91, jan.-mar. 2018. 
formar crenças singulares sobre supostos objetos no ambiente. Ao alucinar o que me parece ser o Ernesto entrando na sala, posso formar crenças como 'aquele cara vai começar a aula'. Minha alucinação serve, inclusive, como evidência interna (em primeira-pessoa) para a crença que tenho. A capacidade da alucinação de disponibilizar crenças singulares, mesmo na ausência de qualquer objeto percebido, sugere que a tentativa de usar o objeto para fixar a particularidade fenomênica é um projeto que já começa equivocado. Mas simplesmente tirar o objeto da jogada e não colocar nada no lugar deixa misteriosa tanto a alucinação quanto a experiência ordinária de ver o Ernesto, em carne e osso, entrar na sala.

O problema central da estratégia adotada pela maioria dos representacionalistas é que se o caráter fenomênico da experiência é fixado pela parte não-singular do conteúdo, a diferença fenomênica entre experiências singulares e não-singulares fica sem qualquer explicação. A importância de tal contraste fica evidente quando consideramos o impacto cognitivo do caráter singular da experiência. Nossa capacidade de entreter pensamentos demonstrativos singulares, por exemplo, está apoiada nesse traço fenomênico. Se aponto para o Ernesto e digo 'ele foi meu professor de lógica', meu interlocutor precisa, para compreender o proferimento, isolar perceptualmente o objeto referido e toma-lo como o valor que preenche a proposição expressa. Só assim meu interlocutor saberá de quem estou falando. Mas tal habilidade depende da capacidade perceptiva de ver o Ernesto enquanto objeto singular, suscetível de servir como referente para minha expressão referencial.

A dificuldade enfrentada pelos representacionalistas é ainda mais evidente quando consideramos a principal perspectiva rival, comumente chamada de realismo ingênuo. ${ }^{7} \mathrm{O}$ realista ingênuo defende uma visão essencialmente relacional da experiência perceptiva. A relação perceptiva é constitutiva da natureza mesma da experiência, sendo concebida como uma relação direta que só se obtêm caso ambos os relata (sujeito e coisa percebida) estejam disponíveis. Ou seja, a experiência exige, para ser o que é, que o relatum mundano, ou o objeto percebido, exista e esteja devidamente relacionado com o sujeito. O realista ingênuo fixa o caráter fenomênico da experiência em termos do objeto percebido. Segundo a famosa expressão de Martin (2004, p. 64), os objetos e propriedades percebidos "conformam os contornos da experiência consciente

7 Dentre os defensores do realismo ingênuo, destacam-se Campbell (2002), Martin (2004), Brewer (2004) e Fish (2009).

Manuscrito - Rev. Int. Fil. Campinas, v. 41, n. 1, pp. 67-91, jan.-mar. 2018. 
do sujeito". ${ }^{8}$ Segundo o realista ingênuo, a fenomenologia da experiência é fixada diretamente pelos objetos mundanos, não cabendo falar em qualquer espécie de representata ou conteúdo que intermedeie a relação sujeito-mundo.

Os realistas ingênuos pretendem explicar a natureza da experiência perceptiva e sua peculiar qualidade fenomênica sem fazer qualquer apelo à relação representacional e à noção de conteúdo. Eles acreditam que o mero apelo aos objetos mundanos e suas propriedades é suficiente para explicar o aspecto qualitativo de nossas experiências. Tal manobra, no entanto, torna o problema em foco ainda mais intratável. Pense, por exemplo, na experiência alucinatória. Quando não há nada no mundo para fixar a fenomenologia da experiência, os realistas ingênuos se veem obrigados a adotar uma teoria disjuntivista da fenomenologia perceptiva. Alguns chegaram ao ponto de defender posturas eliminativistas que negam qualquer fenomenologia propriamente dita para as experiências alucinatórias. ${ }^{9}$ A chamada intuição ingênua' (nä̈ve intuition), que se encontra na base do realismo ingênuo, mistura singularidade fenomênica e singularidade metafísica de tal forma que nenhum esforço posterior é capaz de contornar o problema. A intuição ingênua consiste na tese de que os objetos eles mesmos "conformam os contornos" (shape the contours) da experiência. Isso faz com que a singularidade metafísica, que explica porque um objeto qualquer é um objeto singular, abarque a singularidade fenomênica, que se refere à forma singular como um objeto se apresenta fenomenologicamente na experiência. Ao fazer isso, os realistas ingênuos eliminaram qualquer possiblidade de explicar experiências singulares vazias, e ainda tornaram misteriosa a possibilidade de similitude fenomênica entre experiências de diferentes objetos.

Conforme disse Montague (2011, p. 138), "se não há nada no caráter da experiência que seja essa coisa em particular, não podemos dizer que percebemos um objeto particular, em contraposição a sermos simplesmente afetados

\footnotetext{
${ }^{8}$ No original: “... shape the contours of the subject's conscious experience.” (Martin, 2004, p. 64).

${ }^{9}$ Ver Fish $(2008,2009)$ para a defesa do tipo de disjuntivismo eliminativista mais radical que conheço. Hawthorne \& Kovakovich (2006) e Pautz (2011) fizeram ótimos levantamos críticos das diferentes teorias disjuntivistas oferecidas pelos realistas ingênuos. Pautz, em particular, desenvolve uma profunda crítica ao realismo ingênuo que se aproxima, ao menos no espírito geral, àquela esboçada aqui.
}

Manuscrito - Rev. Int. Fil. Campinas, v. 41, n. 1, pp. 67-91, jan.-mar. 2018. 
causalmente por um objeto particular". ${ }^{10}$ A tentativa de tratar a singularidade fenomênica a partir do objeto representado na experiência incorre no problema apontado. O que precisamos é de uma explicação fenomênica da singularidade, não de um objeto mundano qualquer com o qual estamos relacionados e que nos faz, de alguma forma, termos a experiência que temos. No que se segue, proponho uma solução alternativa ao problema que evite as dificuldades enfrentadas tanto pelos representacionalistas quanto pelos realistas ingênuos. Ao discutir possíveis soluções para esse problema, Schellenberg (2010, p. 45) afirmou:

se uma distinção pode ser traçada entre aquilo que uma experiência é sobre e aquilo que o sujeito toma como sendo aquilo que sua experiência é sobre, então poderemos opor conteúdo e fenomenologia da experiência sem, contudo, pensá-los como sendo inteiramente independentes. ${ }^{11}$

A saída para a dificuldade, acredito, está exatamente em fazer o que foi sugerido por Schellenberg, e é isso que pretendo fazer a seguir.

\section{A solução}

Antes de qualquer coisa, é preciso dividir o trabalho explicativo antes depositado numa única noção de conteúdo. O fato de objetos particulares serem necessários para a individuação da experiência e para a determinação de suas condições de veracidade deve ser separado daquilo que determina o caráter fenomênico da experiência. A tentativa de lidar com essas duas coisas numa tacada só se encontra na raiz do problema a ser enfrentado.

Schellenberg (2010, p. 22) distingue duas noções de particularidade:

\footnotetext{
${ }^{10}$ No original: "If there is nothing in the character of experience which is a this thing-ness, we cannot be said to perceive a particular object, rather than merely be causally affected by a particular object." (Montague, 2011, p. 138; grifo no original).

${ }^{11}$ No original: "If a distinction can be drawn between what an experience is of and what one takes one's experience to be of, then we can drive a wedge between the content and the phenomenology of an experience, without thinking of them as entirely independent." (Schellenberg, 2010, p. 45).
}

Manuscrito - Rev. Int. Fil. Campinas, v. 41, n. 1, pp. 67-91, jan.-mar. 2018. 
(1) "Um estado mental instancia a particularidade relacional se e somente se o sujeito da experiência está perceptualmente relacionado com o objeto particular percebido"12;

(2) "Um estado mental instancia a particularidade fenomênica se e somente se a particularidade encontra-se no escopo de como as coisas parecem para o sujeito, de forma que pareça para o sujeito que há um objeto particular presente."13

O fato de objetos particulares servirem para individuar a experiência lida com a noção relacional de particularidade, mas o aspecto relacional não compreende o aspecto fenomênico. Esses dois aspectos são confundidos de forma emblemática pelo realista ingênuo quando o objeto da relação perceptiva é tomado como diretamente determinando os "contornos" da fenomenologia perceptiva. O representacionalista, por sua vez, incorre no equívoco de tentar fixar o caráter fenomênico da experiência com um conteúdo completamente independente do objeto percebido, eliminando assim qualquer elemento que possa capturar a singularidade fenomênica.

Para evitar os mesmos equívocos das teorias anteriores, proponho a adoção de um fixador para a singularidade fenomênica que não se confunda com o objeto particular presente no conteúdo. Tal elemento, acredito, pode ser satisfatoriamente forjado a partir de uma adaptação livre da célebre teoria de Kaplan (1978) dos indexicais linguísticos para o domínio da experiência perceptiva. ${ }^{14}$ Segundo a teoria de Kaplan, termos indexicais (e.g. 'eu', 'aqui', 'esse', 'aquele', 'hoje') possuem conteúdo em relação ao contexto. O conteúdo do termo 'aqui', por exemplo, num determinado contexto, é a localização onde é proferida a locução; já o conteúdo do termo 'eu', num dado contexto, é o

12 Grifo nosso. No original: "A mental state instantiates relational particularity if and only if the experiencing subject is perceptually related to the particular object perceived." (Schellenberg, 2010, p. 22).

13 Grifo nosso. No original: "A mental state instantiates phenomenological particularity if and only if particularity is in the scope of how things seem to the subject, such that it seems to the subject that there is a particular object present." (Schellenberg, 2010, p. 22).

14 Tal possibilidade foi brevemente cogitada por Tye (2014, p. 304), mas logo em seguida abandonada. Minha proposta surgiu exatamente da exploração de tal alternativa.

Manuscrito - Rev. Int. Fil. Campinas, v. 41, n. 1, pp. 67-91, jan.-mar. 2018. 
falante do proferimento. O conteúdo de uma sentença contendo termos indexicais é uma proposição estruturada contendo o conteúdo dos termos indexicais e o conteúdo dos demais termos. Assim, a sentença 'eu estou em São João del-Rei', proferida por mim durante o IX Colóquio Internacional de Filosofia da Mente, tem como conteúdo uma proposição estruturada contendo eu (o falante no contexto), a cidade de São João del-Rei (o referente do nome próprio), e a relação de 'estar em'. Termos indexicais, na teoria de Kaplan, são funções que levam elementos do contexto para o interior do conteúdo. A função é chamada de 'caráter' (character), e podemos especificá-la sem fazer referência a nenhum contexto em particular. O termo 'eu', por exemplo, tem como caráter a função cujo valor em cada contexto é o falante do proferimento. $\mathrm{O}$ caráter pode ser entendido como um componente do que podemos chamar de conteúdo esquemático. A sentença 'eu estou em São João delRei', independentemente de qualquer contexto, parece já constranger parcialmente os mundos que podem satisfazer o conteúdo que ela expressa, qualquer que seja esse conteúdo. Seja quem for o falante, já sabemos que é preciso que ele esteja em São João del-Rei, e não no Nepal, ou em qualquer outro lugar. Ainda que tal conteúdo esquemático não possa determinar plenamente as condições de verdade do proferimento, parece que já sabemos algumas das condições que precisam ser satisfeitas.

Considere agora o caso de demonstrações falhas, nas quais o caráter não determina nenhum conteúdo no contexto específico. Suponha, por exemplo, que eu acredite que o Ernesto está atrás de mim. Enquanto converso com outra pessoa, aponto para trás, por sobre os meus ombros, e digo: 'esse cara foi meu professor'. Suponha agora que, sem que eu saiba, o Ernesto já tinha ido embora e não havia ninguém atrás de mim. Nesse caso, meu uso da expressão referencial 'esse cara' não denotou coisa alguma. Uma vez que o conteúdo de uma expressão demonstrativa é determinado pelo objeto demonstrado no contexto, meu proferimento não possui nenhum conteúdo específico. Apesar de não ter conteúdo, a sentença proferida ainda assim possui um caráter. Ainda que a função demonstrativa tenha falhado em determinar um objeto para servir de valor e preencher o conteúdo, não faz sentido negar a existência da própria função, independentemente de tal falha. Podemos dizer que a função (o caráter) apresenta as condições que precisam ser satisfeitas para que um conteúdo pleno seja determinado. Só temos uma demonstração falha por que tais condições não foram satisfeitas. 
Sentenças linguísticas demonstrativas e experiências perceptivas são, em muitos sentidos, análogas. Assim como sentenças linguísticas, experiências perceptivas também estão associadas a conteúdos que capturam suas condições de veracidade. A percepção, assim como as expressões demonstrativas, também parece possuir certo tipo de indexicalidade: o conteúdo de uma experiência é dado em função do contexto, ou ambiente experienciado. Experiências perceptivas parecem isolar (single out) objetos do ambiente, fazendo referência a eles. Essa capacidade de isolar elementos do ambiente pode ser entendida como uma espécie de função que mapeia objetos do contexto no conteúdo da experiência. Da mesma forma que a função indexical (o caráter) compõe uma espécie de conteúdo esquemático, podemos ver a função perceptiva como compondo uma espécie de conteúdo esquemático da experiência. Assim como o caráter constitui um 'quase-conteúdo' da sentença, a função perceptiva desempenha papel análogo: ela estabelece condições que precisam ser satisfeitas para que a experiência determine um conteúdo específico.

Daqui em diante, chamarei de conteúdo esquemático esse tipo especial de quaseconteúdo da percepção, composto pela junção da função perceptiva com as propriedades representadas na experiência. Se o conteúdo esquemático possui uma função $f x$ qualquer, e um conjunto de propriedades $P$ supostamente instanciadas pelo objeto determinado pela função, então podemos caracterizar o conteúdo esquemático como sendo $[f x, P]$. Considere, por exemplo, a minha experiência de ver o Ernesto com uma camisa xadrez cor-de-rosa. O conteúdo dessa experiência seria determinado pelo conteúdo esquemático $[f x, P]$. No contexto dado, a função $f x$ determina como valor o Ernesto, e atribui a ele a propriedade $P$ (xadrez \& cor-de-rosa). O conteúdo da experiência, no contexto, consiste em [Ernesto, $P$ ], onde a propriedade $P$ é atribuída a Ernesto. Suponha agora que veja o Genésio, e não o Ernesto, com uma camisa xadrez cor-derosa. Minha experiência do Genésio possuiria o mesmo conteúdo esquemático $[f x, P]$, mas no novo contexto o conteúdo determinado seria [Genésio, $P$ ].

Considere, por fim, que estou apenas alucinando o que me parece ser o Ernesto com uma camisa xadrez cor-de-rosa. Minha experiência alucinatória é interessantemente similar ao caso da demonstração falha. Em ambos os casos, há uma falha em designar um objeto. Nos dois casos, não é possível determinar um conteúdo pleno, havendo uma falha qualquer na relação com o suposto objeto designado. Tal falha é capturada, em ambos os casos, pelo conteúdo esquemático: ele possui uma função que não é satisfeita e, portanto, falha em determinar um valor específico para preencher o conteúdo. Proponho, 
portanto, que a alucinação seja compreendida como um estado mental que possui um conteúdo esquemático no qual a função perceptiva não determina nenhum objeto como valor. Tal falha faz com que alucinações sejam, propriamente falando, privadas de conteúdo perceptivo. Podemos dizer que a alucinação é uma experiência falha: ela pretende ser a percepção de algo, mas falha, assim como a demonstração falha pretende demonstrar algo, mas não consegue. Segundo Tye (2014, p. 301), "experiências visuais fundamentalmente pretendem nos colocar em contato com objetos ao nosso redor". ${ }^{15}$ Nesse sentido, alucinações são estados perceptivos que falham em satisfazer seu propósito fundamental: alucinações não nos colocam em contato com objetos ao nosso redor. Quando alucino o que parece ser o Ernesto com uma camisa xadrez cor-de-rosa, tal experiência possui o conteúdo esquemático $[f x, P]$, mas o contexto é tal que nenhum objeto particular é apanhado pela função $f x$. Nesse caso, a função não determina nenhum valor, não sendo determinado nenhum conteúdo pleno.

Proponho que o conteúdo esquemático seja usado para fixar o caráter fenomênico da experiência. Tal abordagem possibilita que experiências genuínas, como as de ver o Ernesto ou o Genésio, e experiências alucinatórias, compartilharem a mesma fenomenologia. Uma vez que o conteúdo esquemático não inclui nenhum objeto particular, tal possibilidade não suscita mais nenhuma dificuldade. Seguindo minha proposta, a singularidade fenomênica pode ser fixada pela função perceptiva $f x$. Tal função tem o papel de apanhar o objeto no contexto e colocá-lo no conteúdo. Se a função falha em desempenhar seu papel, ainda assim ela continua existindo no conteúdo esquemático como um termo referencial que falha em designar o referente. O sucesso ou não da referência não interfere na fenomenologia da percepção. Uma vez que o caráter fenomênico é equacionado com o conteúdo esquemático, o fato de tal esquema determinar ou não um conteúdo não tem qualquer impacto na fenomenologia perceptiva. O sucesso da função designativa interfere apenas na individuação da experiência, pois esta faz necessariamente referência ao objeto percebido, mas não tem nenhum impacto na forma como tal experiência se apresenta para o sujeito. A minha proposta, ao contrário das abordagens discutidas anteriormente, consegue capturar a distinção entre particularidade relacional e

15 No original: “...what visual experiences fundamentally aim to do is to put us in contact with objects around us." (Tye, 2014, p. 301; grifo no original).

Manuscrito - Rev. Int. Fil. Campinas, v. 41, n. 1, pp. 67-91, jan.-mar. 2018. 
particularidade fenomênica, detectada por Schellenberg (2010) como sendo a raiz do problema.

A afirmação de que alucinações não possuem conteúdo propriamente dito pode soar estranha para muitos representacionalistas. Afinal de contas, a teoria representacionalista afirma que a experiência perceptiva consiste fundamentalmente em um sujeito estar num certo estado representacional definido em termos de seu conteúdo. Se não há conteúdo, qual o sentido de caracterizar a alucinação como uma 'experiência perceptiva'? O conteúdo, como sabemos, pretende capturar a forma como o mundo é representado segundo a experiência. O que parece ter passado desapercebido é que, no caso da experiência alucinatória, o mundo não é representado como sendo de nenhuma maneira específica. A alucinação, nesse sentido, é um estado sui generis. Para compreende-la, é preciso distinguir diferentes condições de satisfação que são capturadas pela noção de conteúdo: (1) uma primeira condição apreende os requisitos necessários para que haja uma genuína relação perceptiva com objetos no mundo; (2) uma segunda condição determina aquilo que torna um episódio experiencial verídico ou não. A primeira condição, tal como o conteúdo esquemático, pode ser especificada sem fazer referência ao contexto específico. Nesse primeiro nível, temos representações esquemáticas como 'aquele (suposto) objeto possui a propriedade $P$ '. Se esta condição não é satisfeita porque nenhum objeto é designado, temos uma falha referencial: o sujeito não está devidamente conectado ao ambiente. A falha, neste caso, não consiste em dizer que o mundo é assim-e-assado, mas o mundo é de outra forma; a falha consiste em nem chegar a afirmar nada de específico sobre o mundo. Daí a descrição da alucinação como uma experiência falha.

O fato de a alucinação não possuir conteúdo stricto sensu captura, assim, sua natureza peculiar: uma alucinação, propriamente falando, não é nem verídica nem inverídica. O tipo de erro que a caracteriza não a coloca em condição de ser nem uma coisa nem outra. Ao falhar em estar relacionada com o mundo da forma apropriada, a alucinação nem chega a ser sobre um estado de coisas especifico do mundo. Propriamente falando, não há como mudar o mundo e tornar uma alucinação verdadeira, pois ela nem chega a determinar uma forma específica como o mundo deveria ser.

É importante ressaltar que a proposta aqui apresentada não elimina a noção clássica de conteúdo. Ela apenas adiciona a esta noção uma outra: o conteúdo esquemático. Tal distinção permite que o trabalho explicativo que antes estava inteiramente concentrado numa única noção seja devidamente dividido. A 
noção de conteúdo continua fundamental para lidar com as questões ontológica e cognitiva. Não há como individuar uma experiência genuína sem fazer referência ao objeto percebido. Também não é possível explicar as capacidades cognitivas de experiências singulares sem fazer referência ao objeto da experiência. Entretanto, a experiência alucinatória obviamente não pode ser individuada da mesma forma. Ela simplesmente não tem nenhum objeto que possa desempenhar tal papel. Proponho, portanto, que as alucinações sejam individuadas em termos de conteúdos esquemáticos, que nada mais são que tipos fenomênicos que podem ser instanciados em diferentes ocorrências experienciais.

A diferença entre as constituições metafísicas de experiências genuínas e alucinatórias reflete uma importante assimetria entre elas. A experiência genuína precisa ser individuada em termos de objetos particulares para que seus poderes cognitivos sejam explicados. Alucinações, ao contrário, não possuem o mesmo tipo de poderes cognitivos. Alucinações numericamente distintas com o mesmo caráter fenomênico possuem exatamente os mesmos poderes cognitivos. A ausência de objeto percebido impede que alucinações possam disponibilizar pensamentos de re sobre o que quer que seja. Alucinações simplesmente não disponibilizam uma res para o pensamento. A minha proposta divide as coisas de tal forma que cada elemento oferece exatamente o precisa ser oferecido, evitando assim os problemas anteriores.

\section{A proposta de Schellenberg}

A proposta aqui esboçada guarda uma profunda similaridade estrutural com a proposta defendida nos últimos anos por Susanna Schellenberg (2010, 2013, 2014, 2016). O presente artigo surgiu, evidentemente, de um diálogo bem próximo com suas ideias. Apesar de, em grande medida, seguir a forma como ela situa o problema e suas principais distinções conceituais, nossas propostas divergem em alguns prontos cruciais. Para evitar mal-entendidos e destacar o caráter inovador da minha proposta, termino esse artigo destacando as nossas diferenças. ${ }^{16}$

\footnotetext{
16 Agradeço ao parecerista anônimo que me alertou para a necessidade de tornar esse ponto explícito.
}

Manuscrito - Rev. Int. Fil. Campinas, v. 41, n. 1, pp. 67-91, jan.-mar. 2018. 
Schellenberg defende que a experiência alucinatória possui um "conteúdo fregeano lacunar" (Fregean gappy content). Tirando a afirmação de que experiências são explicadas em termos de conteúdo representacional, que explicita nossa filiação comum a uma abordagem representacionalista, minha proposta não é nem fregeana, nem lacunar. Grosso modo, o que faço é retirar a roupagem fregeana de sua teoria enquanto retenho seu esqueleto estrutural. $\mathrm{O}$ resultado, conforme argumento a seguir, parece-me não apenas teoricamente mais enxuto e econômico, mas até mesmo mais potente e apropriado para explicar a natureza da experiência alucinatória. Em grande medida, as questões tratadas aqui são ortogonais ao infindável debate entre fregeanos e russellianos. Achar uma solução que não se comprometa com nenhum dos lados desse debate representa um importante passo teórico; afinal de contas, é uma grande vantagem se livrar de comprometimentos teóricos desnecessários. ${ }^{17}$

A experiência perceptiva, para Schellenberg, deve ser concebida em termos de conteúdos de re fregeanos. O conteúdo perceptivo seria composto por "modos de apresentação" (modes of presentation) que capturam a forma como os objetos são percebidos pelo sujeito. ${ }^{18} \mathrm{~A}$ abordagem fregeana, conforme argumenta a autora, permitiria a adição de uma camada adicional à noção de conteúdo que não se encontra disponível para os russellianos. Da mesma forma que a proposição (Gedanke), segundo a apropriação que Schellenberg faz de Frege, é composta por sentidos (Sinn) que podem prescindir de um referente

${ }^{17}$ Apesar de usar um vocabulário muitas vezes tendencioso ao russellianismo, acredito que minha proposta pode se manter neutra quanto a qualquer teoria específica sobre a natureza do conteúdo perceptivo. Feitas as devidas alterações terminológicas, minha proposta pode ser apropriada por quem defende proposições de tipo fregeana, ou russelliana, ou conjuntos de mundos possíveis, ou seja lá qual for a preferência do freguês. Ainda que tenha comprometimentos russellianos que possam ter me passado desapercebidos, minha proposta poderia, então, ser vista como uma versão russelliana da proposta de Schellenberg, o que serviria para eliminar a necessidade, postulada por ela, de comprar todo o pacote fregeano.

18 A proposta de Schellenberg engloba tanto da percepção de objetos particulares quanto de suas propriedades. Segundo argumenta, instâncias particulares de propriedades também são perceptualmente referidas por modos de apresentação de re. Uma vez que esse artigo tem como foco a percepção de objetos particulares, não pretendo avançar aqui nenhuma teoria específica sobre a percepção de propriedades. Visando maior foco e economia, opto, portanto, por deixar essa questão de lado.

Manuscrito - Rev. Int. Fil. Campinas, v. 41, n. 1, pp. 67-91, jan.-mar. 2018. 
(Bedeutung), o conteúdo perceptivo seria composto por modos de apresentação que podem falhar em determinar um referente.

A noção de modo de apresentação, quando transposta para o campo da experiência perceptiva, precisa ser compreendida de uma forma específica. Primeiramente, é preciso distinguir os modos de apresentação de dicto e de re (Schellenberg, 2010, p. 36). O modo de apresentação de dicto estabelece uma relação de satisfação semântica entre conteúdo e objeto: o conteúdo apresenta uma descrição, e o objeto que porventura satisfizer essa descrição é o objeto determinado pelo conteúdo. ${ }^{19}$ Segundo argumenta a autora, tal modo de apresentação é incapaz de acomodar a particularidade relacional da experiência perceptiva. A não ser que o modo de apresentação faça referência ao objeto particular percebido, o fato mesmo de que uma experiência é sobre um dado objeto particular, em contraposição a qualquer outro objeto, ainda que fenomenicamente idêntico, restaria inteiramente misterioso. Além de não explicar a referência direta que a experiência perceptiva faz à sua respectiva res, o modo de apresentação de dicto também caracteriza equivocadamente suas condições de veracidade: quando tenho uma experiência visual do Ernesto, por exemplo, somente o Ernesto pode tornar verídica a minha experiência.

O modo de apresentação de re foi concebido de diferentes formas, mas nem todas servem à caracterização do conteúdo perceptivo. Evans (1982) e McDowell (1984), por exemplo, conceberam o sentido de re como fazendo referência ao objeto de tal forma que, na ausência do referente (res), nenhum conteúdo poderia ser determinado. Nessa abordagem, um modo de apresentação de re que não determina um referente (Bedeutung) seria uma aberração, uma impossibilidade. Tal noção de modo de apresentação, que é radicalmente dependente de objeto, seria incapaz de explicar a particularidade fenomênica de experiências alucinatórias. A tentativa de uma abordagem disjuntivista da fenomenologia perceptiva, que foi adotada por esses autores, incorre no problema detectado acima na teoria do realismo ingênuo. A alternativa encontrada por Schellenberg (2010, p. 37) foi forjar um modo de apresentação de re que seja apenas parcialmente dependente de objeto (partly object-dependent, ou object-related).

O caminho esquematizado nos parágrafos anteriores levou a autora a conceber o modo de apresentação de re como um conceito parcialmente

19 Essa caracterização dos modos de apresentação de dicto foi retirada de Chalmers (2006, p. 99).

Manuscrito - Rev. Int. Fil. Campinas, v. 41, n. 1, pp. 67-91, jan.-mar. 2018. 
dependente de objeto, definido em termos das habilidades discriminatórias exigidas para a sua possessão. ${ }^{20} \mathrm{O}$ conteúdo perceptivo, portanto, seria composto por modos de apresentação de re parcialmente dependentes de objeto que possuem condições de possessão determinadas por conceitos. Se representarmos esquematicamente o conceito associado ao modo de apresentação de re como $M A_{r}($ ), e o objeto percebido como o, o conteúdo determinado quando se percebe o objeto seria representado por $M A_{r}(o)$. No caso de uma alucinação, uma vez que o conceito não discrimina nenhum objeto, o conteúdo teria uma lacuna, ou um espaço vazio (gap), que poderia ser representado por $M A_{r}\left(\_\right)$. Dessa forma, ela distingue o conceito associado ao modo de apresentação do output desse conceito, que seria uma espécie de modo de apresentação preenchido. O modo de apresentação pode ser preenchido por um objeto particular ou por uma lacuna (gap). O conteúdo perceptivo, ao fim, é composto por modos de apresentação de re preenchidos.

Portanto, Schellenberg defende que alucinações possuem conteúdos de re lacunares (gappy de re contents). Ela argumenta que fregeanos, ao contrário de russellianos, não precisam ter medo de conteúdos lacunares. Para o russelliano, uma vez que a lacuna (gap) ocupa o lugar de um objeto no conteúdo, ele parece constituir um misterioso objeto de tipo especial. Já para o fregeano, que preenche o conteúdo com modos de apresentação, a lacuna não seria problemática. Mas será que precisamos mesmo nos comprometer com uma teoria fregeana do conteúdo? E será que o problema de introduzir lacunas no conteúdo desaparece se adotamos uma perspectiva fregeana? Não perseguirei aqui nenhuma dessas questões; apenas alerto para alguns dos desafios acarretados pelos comprometimentos assumidos pela autora.

Segundo a proposta que defendi na seção anterior, experiências alucinatórias não têm conteúdo. Uma vez que o caráter fenomênico é explicado pelo conteúdo esquemático, simplesmente eliminei a noção de um conteúdo alucinatório propriamente dito. Ao contrário de Schellenberg, não preciso fornecer nenhuma explicação do que seriam conteúdos lacunares, pois não postulo nada parecido. Schellenberg pretende explicar, ao mesmo tempo, a particularidade relacional e a particularidade fenomênica da experiência

20 Schellenberg (2010) enfatiza que sua noção de conceito é perfeitamente compatível com a tese de que o conteúdo perceptivo é não conceitual: as discriminações perceptivas exigidas para a posse dos conceitos relevantes podem ser instanciadas por criaturas pouco sofisticadas que não articulam conceitos linguísticos.

Manuscrito - Rev. Int. Fil. Campinas, v. 41, n. 1, pp. 67-91, jan.-mar. 2018. 
perceptiva. Se nos atermos a esse duplo desiderata, veremos que a minha proposta é mais econômica e dá os resultados desejados. Nós dois fixamos o caráter fenomênico com elementos apenas parcialmente dependentes de objetos: no meu caso, o conteúdo esquemático, no caso dela, o conceito ou modo de apresentação não preenchido. Uma vez que a alucinação não precisa de nenhum elemento capaz de fundar a particularidade relacional, pois ela não está relacionada a nenhuma res específica, faz-se desnecessário introduzir um conteúdo para ela.

A própria Schellenberg (2010, p. 40) distingue duas formas nas quais uma experiência pode ser dita acurada ou não: "uma forma é o conteúdo fazer uma afirmação sobre a situação que não é acurada. A segunda forma é ele falhar em fazer uma afirmação acurada sobre a situação". ${ }^{21}$ Em sua concepção, uma vez que alucinações têm conteúdo, elas possuem condições de veracidade assim como qualquer outro estado perceptivo, mas por serem lacunares, elas seriam necessariamente inacuradas. Esse veredicto sobre experiências alucinatórias me parece equivocado. Falhar em fazer uma afirmação acurada não poderia ser simplesmente equacionado com fazer uma afirmação necessariamente inacurada. Se falho em afirmar algo, seja lá o que estou fazendo não poderia ser o tipo de coisa passível de ser verídico ou não, pois suas condições de veracidade simplesmente não foram plenamente estabelecidas. Ainda que um episódio alucinatório possa ser fenomenologicamente idêntico a um encontro perceptivo genuíno com o mundo, uma vez que ele falha em se referir ao mundo da forma apropriada, ele simplesmente perde o direito de ser sobre um estado do mundo específico. Um enunciado falso sobre nada, preenchido por uma lacuna, não é a mesma coisa que uma tentativa falha de enunciar o que quer que seja. O tipo específico de erro perceptivo da alucinação é sui generis: não se trata de uma afirmação falsa sobre um item que não existe, mas da falha mesma de se referir a qualquer item, e, portanto, de afirmar o que quer que seja. Segundo minha proposta, alucinações não são afirmações falsas, mas falsas afirmações. Acredito que tal abordagem captura melhor a natureza sui generis das experiências alucinatórias.

${ }^{21}$ No original: "... one way is for the content to make a claim about the situation that is not accurate. A second way is for it to fail to make an accurate claim about the situation" (Schellenberg, 2010, p. 40).

Manuscrito - Rev. Int. Fil. Campinas, v. 41, n. 1, pp. 67-91, jan.-mar. 2018. 
Imagino que Schellenberg talvez aproximaria minha proposta da teoria de conteúdos múltiplos (multiple contents view) ${ }^{22}$, segundo a qual a experiência perceptiva possui diferentes camadas (layers) de conteúdo, cada uma satisfazendo as diferentes demandas explicativas, sendo cada camada associada a diferentes condições de satisfação. O principal problema de tal visão, segundo Schellenberg (2010, p. 42), é a dificuldade de explicar como os vários conteúdos se relacionam. A minha proposta evita esse problema uma vez que conteúdo e conteúdo esquemático não são definidos em termos completamente independentes, e nenhuma das camadas é satisfeita por relações inteiramente não dependentes de objetos. Seja qual for a relação relevante que conceitos e conteúdos guardam entre si na teoria de Schellenberg, o mesmo parece se aplicar à relação que postulo entre conteúdos esquemáticos e conteúdos. A exigência de que os modos de apresentação perceptivos sejam de re e parcialmente dependentes de objetos se aplica, igualmente, à forma como meus conteúdos esquemáticos determinam seus conteúdos. Enquanto tal, a função perceptiva que toma objetos como inputs e entrega conteúdos como outputs parece ser tão de re e dependente de objetos quanto se deseja, sem a necessidade de jogar no conteúdo a própria função que o determina, assim como faz Schellenberg ao introduzir seus modos de apresentação no próprio conteúdo da experiência.

A explicação do que faz um estado perceptivo instanciar uma certa função perceptiva pode ser dada, assim como em Schellenberg, em termos de habilidades discriminativas. No entanto, minha proposta é neutra quanto a tal abordagem e admite explicações alternativas da nossa capacidade de referir perceptivamente a objetos particulares do ambiente. Quando Kaplan (1978) apresentou sua teoria dos demonstrativos linguísticos, ele ofereceu uma descrição esquemática de como o caráter mapeia o contexto no conteúdo. Cada termo demonstrativo foi descrito como uma função que toma um determinado item do contexto como valor e entrega um conteúdo como resultado. Em nenhum momento, Kaplan explica como o caráter busca seu valor no contexto. Afinal de contas, quando um falante diz 'Está chovendo agora', como a fatia de tempo relevante é buscada (picked out) no contexto? Kaplan não faz a menor ideia, e não é disso que trata especificamente a sua teoria. Provavelmente, uma resposta adequada a essa questão exigiria pesadas doses de metafísica e ciência

\footnotetext{
22 Versões dessa teoria são defendidas, por exemplo, por Horgan e Tienson (2002) e por Chalmers (2006).
}

Manuscrito - Rev. Int. Fil. Campinas, v. 41, n. 1, pp. 67-91, jan.-mar. 2018. 
empírica. ${ }^{23}$ Assim como Kaplan, pretendo deixar tais questões completamente abertas. Grosso modo, minha proposta apenas desenha, esquematicamente, uma certa estrutura teórica capaz de acomodar a singularidade fenomênica no quadro de uma teoria representacionalista definida em termos os mais neutros possíveis. A proposta de Schellenberg é muito mais ambiciosa, pretende explicar muitas outras coisas, e assume, consequentemente, comprometimentos teóricos muito mais pesados. Ao fazer o que faço, pretendo mostrar que um certo esqueleto esquemático pode ser divorciado do seu projeto como um todo, e tal esqueleto pode depois ser preenchido com a carne da preferência do freguês. Muitos dos comprometimentos que Schellenberg entende necessários à sua abordagem são, no fundo, partes de um projeto muito mais amplo e controverso do que o que pretendi tratar nesse artigo.

\section{Considerações finais}

Conforme argumentei acima, as principais teorias do conteúdo perceptivo são incapazes de explicar o caráter singular da experiência perceptiva. Tal dificuldade se origina da ausência de uma série de distinções que acaba tornando o problema aparentemente insolúvel. Após analisar brevemente as principais deficiências do representacionalismo e do realismo ingênuo, esbocei uma proposta que pretende tornar não-problemático o fato trivial de percebermos objetos particulares que se apresentam enquanto tais em nossas experiências perceptivas. Em seguida, procurei destacar as diferenças e a vantagens da minha proposta em relação àquela apresentada por Susanna Schellenberg. A proposta, assim como as críticas às demais alternativas, são reconhecidamente apresentadas de forma breve e esquemática. Tal se deve não apenas às limitações de espaço, mas também ao caráter ainda embrionário da proposta. Espero, ao menos, ter conseguido apontar um caminho promissor. Uma teoria mais robusta precisaria determinar explicitamente a função perceptiva e como ela se relaciona com os estados cognitivos superiores.

\footnotetext{
23 Pense, por exemplo, nas seguintes questões: O que é uma fatia de tempo (time-slice)? Como nos relacionamos com tais coisas? Quais mecanismos sensórios estão sintonizados (co-variam, rastreiam) os objetos e propriedades relevantes? Como tal habilidade surgiu em criaturas como nós? $O$ que nos permite representar perceptualmente tais coisas?
}

Manuscrito - Rev. Int. Fil. Campinas, v. 41, n. 1, pp. 67-91, jan.-mar. 2018. 
Apesar do muito que resta ser feito, e do caráter reconhecidamente incompleto, espero ao menos ter justificado que a proposta vale a aposta.

\section{Referências}

Bayne, T. \& Montague, M. (eds.). Cognitive Phenomenology. Oxford: Oxford University Press, 2011.

BREWER, B. "Realism and the Nature of Perceptual Experience". Philosophical Issues, 14 (1), pp. 61-77, 2004.

Brogand, B. (ed.). Does Perceptions have Contents? Oxford: Oxford University Press, 2014.

CAMPBell, J. Reference and Consciousness. Oxford: Oxford University Press, 2002.

Chalmers, D. (ed.). Philosophy of Mind: Classical and contemporary readings. Oxford: Oxford University Press, 2002.

"Perception and the Fall from Eden". In: T. S. GENDLER; J. HAWTHORNE (eds.) (2006), pp. 49-125.

Crane, T. Elements of Mind. Oxford: Oxford University Press, 2001.

DretSKe, F. Naturalizing the Mind. Cambridge, MA: The MIT Press, 1995.

Evans, G. The Varieties of Reference. Oxford: Clarendon Press, 1982.

FISH, W. "Disjunctivism, Indistinguishability and the Nature of Hallucination". In: A. HADDOCK; F. MACPHERSON (eds.) (2008), pp. 144-167. Press, 2009.

Perception, Hallucination, and Illusion. Oxford: Oxford University

Gendler, T. S. \& HaWthorne, J. (eds.). Perceptual Experience. Oxford: Clarendon Press, 2006.

Grice, H. P. The Causal Theory of Perception. Proceedings of the Aristotelian Society, Supplementary Volumes, 35 (1), pp. 121-152, 1961.

Haddock, A. \& Macpherson, F. (eds.). Disjunctivism: Perception, Action, Knowledge. Oxford: Oxford University Press, 2008.

Manuscrito - Rev. Int. Fil. Campinas, v. 41, n. 1, pp. 67-91, jan.-mar. 2018. 
Hawthorne, J. \& Kovakovich, K. "Disjunctivism". Proceedings of the Aristotelian Society, Supplementary Volumes, 80 (1), pp. 145-83, 2006.

Horgan, T. \& TIENSON, J. "The intentionality of phenomenology and the phenomenology of intentionality”. In: D. CHALMERS (ed.), pp. 520533, 2002.

KAPLAN, D. "On the Logic of Demonstratives". Journal of Philosophical Logic, 8 (1), pp. 81-98, 1978.

LyCAN, W. Consciousness and Experience. Cambridge, MA: The MIT Press, 1996.

MacPherson, F. \& Platchias, D. (eds.). Hallucination: Philosophy and Psychology. Cambridge, MA: The MIT Press, 2013.

Martin, M. "The Limits of Self-Awareness". Philosophical Studies, 120 (1), pp. 37-89, 2004.

MCDOWELL, J. “De re senses”. Philosophical Quarterly, 34, pp. 283-294, 1984.

Montague, M. "The phenomenology of particularity". In: T. BAYNE; M. MONTAGUE (eds.), pp. 121-140, 2011.

PAuTZ, A. "Can Disjunctivists Explain Our Access to the Sensible World?" Philosophical Issues, 21 (1), pp. 384-434, 2011.

SCHELLENBERG, S. "The particularity and phenomenology of perceptual experience”. Philosophical Studies, 149 (1), pp. 19-48, 2010.

"Externalism and the Gappy Content of Hallucination". In: F. MACPHERSON; D. PLATCHIAS (eds.), pp. 291-311, 2013.

"The relational and representational character of perceptual experience". In: B. BROGAARD (ed), pp. 199-219, 2014.

"Perceptual Particularity". Philosophical and Phenomenological Research, 93 (1), pp. 25-54, 2016.

SIEGEL, S. The Contents of Visual Experience. Oxford: Oxford University Press, 2010.

TYE, M. Ten Problems of Consciousness: A Representational Theory of the Phenomenal Mind. Cambridge, MA: The MIT Press, 1995. 
Consciousness Revisited: Materialism without Phenomenal Concepts. Cambridge, MA: The MIT Press, 2009.

"What is the Content of a Hallucinatory Experience?" In: B. BROGAARD (ed.), pp. 291-309, 2014. 